\title{
Great Effect of Fallopia Multiflora and Other Herbs in Poliosis Treatment
}

\author{
Huynh Tan Hoi*
}

\section{Huynh Tan Hoi*}

Language department, FPT University VIETNAM.

\section{Correspondence \\ Huynh Tan Hoi}

Language department, FPT University, VIETNAM.

E-mail: hthcolin@gmail.com

History

- Submission Date: 02-07-2020;

- Review completed: 02-08-2020;

- Accepted Date: 06-08-2020

DOI : 10.5530/pj.2020.12.219

Article Available online

http://www.phcogj.com/v12/i6s

\section{Copyright}

(c) 2020 Phcogi.Com. This is an openaccess article distributed under the terms of the Creative Commons Attribution 4.0 International license.

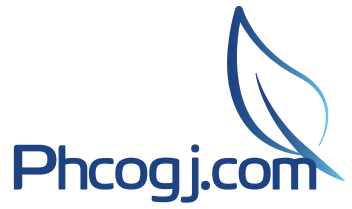

\begin{abstract}
Nowadays, many people with gray hair or poliosis soon lose their confidence in life. Early gray hair is not necessarily a sign of age, but also a disease of many causes. Although not dangerous to health, but gray hair soon loses the aesthetics, making us inferiority, inferiority complex in work and life. This article discusses some herbal remedies that Vietnamese use. Its effects are quite effective and help many people lead a healthier and more confident life.

Key words: Fallopia multiflora, Health, Poliosis, Folk treatment.
\end{abstract}

\section{INTRODUCTION}

The story of gray hair from time to time is only mentioned in the elderly or people in the middle age, a very small number of people with gray hair when they are young are called bad blood people. But until now, the percentage of gray-haired people has increased even more. ${ }^{1}$ Some studies show that $1 / 4$ of people from 24 to 35 years of age have gray hair, of which 20-year-olds have white hair. So, what are the causes and appropriate therapies to help patients be more confident in life?

\section{CAUSES OF EARLY POLIOSIS}

An adult has more than 100,000 hairs. In the hair germ there are pigment cells that produce melanin pigment particles to create skin color, hair color. If these cells have a lot of melanin containing dark pigments, the hair will be black, shiny and vice versa. Early gray hair can also be caused by a genetic or a mutated or damaged gene. ${ }^{2}$

The cause of gray hair can also be due to the body lacking of essential vitamins and minerals, especially 2 types of vitamins B and E or suffering from diseases such as pernicious anemia (usually due to vitamin B12 deficiency) or Werner syndrome (a disease that includes early aging symptoms in the 30s). The abuse of drugs, especially antibiotics, some drugs cause hair loss also make the hair look pale like lithium drugs commonly used to treat manicdepressive disorder, methotrexate commonly used treatment of cancer and rheumatoid arthritis. ${ }^{3}$ Smokers often get four times earlier poliosis than non-smokers. Poliosis can be a result of this deficiency, especially B12 and vitamin E reduce the production of pigment. Weakened organs are also major causes of gray hair.

People who work too often cause fatigue, weakness or an unbalanced diet. Meals can have too much meat and sweets, Few green vegetables and fruits. If we drink a lot of alcohol, beer, coffee or smoke a lot, it also affects the hair color. Patients can also expose their hair to sunlight for too long or use too many dyes and cosmetics that are harmful to the hair. ${ }^{4}$
When the white hair began to appear, many people worried and pulling hair is a method of choice. Not only eliminating fibers, pulling hair also brings a relaxing and pleasant feeling. However, this is not recommended because it can damage the hair follicles, the nerves that connect to the hair follicles. Besides, pulling out gray hair regularly will thin the hair. Hair color helps people with gray hair before age more confident. ${ }^{5}$ However, when dyeing our hair, be careful because there may be some dye-related complications such as contact dermatitis, damage and hair loss. Therefore, we should dye our hair only when it is really necessary, avoid using the color too dark and need to wash our hair thoroughly so that the medicine does not remain on the scalp. ${ }^{4}$

Poliosis is considered as a condition of deficiency or reduction of melanin in the body of the affected hair Poliosis appears to be one, many patches or all of the hair, white or gray hair on the haired parts of the body, usually found on the scalp but can also affect eyebrows, eyelashes or other positions.

Due to industrial environment, bad environment, unhealthy living environment or in response to fashion, the way of dyeing hair as we like is also the factors that lead to this situation. In addition, genetic factors, or due to hair follicles are not provided with enough nutrients and melanin pigments make hair strands will not be colored. ${ }^{6}$

Another possible cause of $\mathrm{g}$ poliosis is due to a thyroid problem (hypothyroidism or hyperthyroidism) which causes the production of hormones in the body to be delayed and hair to be one of the body's organs to suffer a lot. most affected. Some of the basic causes of premature graying include genetic factors, an unbalanced diet, excessive use of cosmetics, smoking, hormone disorders, substance abuse, and especially are antibiotics, environmental effects, stress fatigue, lack of nutrients in the body.

Poliosis, which affects both adults and children, can occur due to a genetic defect of melanin formation, due to the natural destruction of melanocytes in the hair roots or from hair follicles and hair follicles. hurt. Anxiety, nervousness, insomnia, body weakness, 
postpartum women or old age factors trigger chain reactions that affect the action of melanocyte, disturbance of melanin synthesis determines the color of hair. ${ }^{5}$ The cause of gray hair is the aging of the body, causing melanocytes to gradually produce less melanin pigments. Genetic factors play the most important role in determining when our hair is gray, but it can also be caused by conditions that damage hair follicles such as vitiligo, alopecia areata, depigmented moles, piebaldism (gray hair), tuberous sclerosis, etc.

Psychological trauma, physical shock, or other stressful experiences can cause hair loss, sometimes temporarily. Anxiety, stress, fatigue or disturbances in the central nervous system and peripheral nerves also affect the amount of nutrients that prevent hair from being nourished and premature aging to turn white. ${ }^{8}$

Poliosis seems simple but quite complicated. Aesthetically speaking, poliosis makes people get old and lack confidence in life, on the other hand, according to the scientists who studied, balding and poliosis are signs that the body is getting old too fast, poliosis or bald men in their 20 s or 30 s are at a higher risk for heart disease.

People with hair loss or hair discoloration before age 40 are five times more likely to experience heart problems, higher than obesity, a factor that increases the risk of heart disease by four times. When encountering the case of poliosis, people often think of the first option is dyeing hair. However, the dye only works to temporarily blacken the hair, not cure the root of poliosis early, and in today's dyes contain a lot of chemicals such as lead, bismuth, preservative formaldehyde. ${ }^{9}$ Part of highly toxic chemical hair dyes, which contain PPD, which penetrates into the bloodstream will cause mutations and cancer or damage reproductive function in both men and women, substances that cause oxidation causes hair to age quickly and seriously affects human health, if overuse of hair will lead to tangles, not enough nutrients, so poliosis is more likely to break off easily. ${ }^{3}$ Also plucking gray hair accidentally loses the thin film surrounding the hair, hair is prone to grow backwards causing scalp itching and gradually appear pimples, hair follicles atrophy gradually risk not growing hair again, leading to bald head. The first hair treatment used by $80 \%$ of people today is the use of shampoos with ingredients such as ginseng, but still not achieving the desired effect, although the use of these herbs is quite good. Undeniably the role and utility of holophone in the active treatment of poliosis, but it can cause poisoning to the user

\section{CURRENT TREATMENTS}

There is currently no specific medicine to permanently change the color of hair affected by poliosis. The simplest, most effective and least expensive method is to dyeour hair or other means of covering our white hair. At the same time, the use of functional foods such as cheviton, "black forever", "herba hair", etc. but this has not been verified and determined good results in poliosis treatment.

Another good way to benefit our hair is to add the necessary nutrients. So to keep hair healthy, we need to pay attention to ensure daily nutrition for hair. To keep our hair healthy and prevent graying of hair early, there are a few small tips about what foods to eat and which foods to limit to help with hair growth. Protein is the main constituent of hair. Food proteins of animal origin, such as eggs, fish, milk, lean meat, liver, etc. are better for hair than plant proteins. However, soy should be used because in addition to providing protein, it also contains less fat that is harmful to hair. Iron is the main ingredient that helps hair grow faster. Iron-rich foods like poultry, soy, wheat, veal, eel, beef heart, beef, peanuts and egg yolks. Dried fruits like dates, raisins, dark vegetables like cruciferous vegetables and grains also contain iron. ${ }^{10}$

Zinc is an important trace element that prevents hair loss. It is involved in protein synthesis and cell division. This one plays an important role in attaching hair follicles. When the body has a low zinc content, the hair follicles will weaken and that is why the hairs cannot afford to cling to the scalp and fall off. Foods that are rich in zinc to supply hair are cockles, fresh seafood, red meats, young wheat, cheese, chestnuts. Vitamin $\mathrm{C}$ should be added from fresh fruits such as oranges, berries and lemons to stimulate the body to receive iron. We should limit tea and coffee consumption because they have the opposite effect. $B$ vitamins are important for keeping hair, skin and scalp healthy. Lack of B vitamins can lead to anemia, neurological problems, scalp inflammation, early gray hair and hair loss.

Foods rich in fat is not suggested because it increases the content of testosterone - one of the causes of hair loss, in addition to making the hair dry, affecting the normal growth of hair. Besides, we should limit foods high in sugar and grease, foods containing many acids, acidic foods, fast foods, vegetables processed in the form of fermentation, oily fried foods to have strong and beautiful hair.

In order to prevent poliosis early, there is no cure for poliosis at the beginning, however, it can be prevented and reversed by increasing the intake of vitamins and minerals for the body. Particular attention should be paid to vitamins A, C, E, vitamin B5, riboflavin and folic acid. We should limit the use of dyes and cosmetics harmful to your hair. We need to protect our hair with a hat when going out in the sun. We also retain healthy lifestyle, enough sleep, keep us comfortable and build a reasonable diet. ${ }^{8}$ We should eat plenty of green vegetables and fruits such as dark green leafy vegetables, cabbage, onions, pears, raspberries, cherries, apricots. The last one is to limit our consumption of alcohol and stimulant drinks.

\section{GREAT EFFECT OF NATURAL HERBS}

\section{The combination of coconut oil and lemon}

Coconut oil and lemon are effective blends for the treatment of poliosis, which are rich in vitamins and nutrients, and antioxidants that help prevent the formation of gray hair. Moisturizing and balancing hair nutrients, helping hair strong and shiny. ${ }^{11}$ We can mix the mixture of coconut oil and lemon in proportion. Apply the mixture evenly on the hair and gently massage the nutrients into the hair, then wait for 30 minutes, rinse with water and we can ise this method 3-4 times per week (Figure 1).

\section{Medicinal remedies from fallopia multiflora according to folk experience}

Fallopia multiflora can treat damaged blood, palpitations, dizziness, tinnitus, constipation, dryness, loss of hair or graying hair, etc. Patients can use 20 grams of ginger, 20 grams of dark ginseng and 20 grams of biogeography, decoction and divide the drink throughout the day.

This medication helps patients improve bones, blood and health in an active way. We can use streptocaulon juventas Merr and fallopia multiflora with equal amounts. ${ }^{12}$ Then soak them in hog-wash for 3 nights. In the end, grind it and cook with honey, make small balls (or pills), then drink it with alcohol, drink 50 pills per day. We should take this medication at hungry time to promote the therapeutic effect (Figure 2)

\section{Ways to use fallopia multiflora}

In the old days, the method of defensive emblem was mainly for drinking, making pills, or soaking alcohol. Nowadays, with modern technology, it is formulated into convenient forms such as powder, capsules, instant tea, etc.

There are a few simple ways to use fallopia multiflora but very convenient. First is to use fallopia multiflora (60 g), 3 eggs of chicken eggs. We can slice fallopia multiflora $(30 \mathrm{~g})$, cook it with water to get the condensed liquid, then mix it with the eggs and cook the mixture again for daily use. 
Second is to use fallopia multiflora $(30 \mathrm{~g}), 3$ apples, rice $(100 \mathrm{~g})$ and red sugar $(50 \mathrm{~g})$. After soaking fallopia multiflora in water for 2 hours, cook it for an hour to get the condensed liquid, then cook with rice and apples until the mixture becomes porridge, patients can add more sugar for this food.

Third is to use fallopia multiflora (20 g), angelica sinensis $(60 \mathrm{~g})$, rehmannia glutinosa (Gaertn.) Libosch. ex Steud (80 g), honey (50 g), white wine $2,500 \mathrm{ml}$. The herbs are shredded and wrapped in a cloth bag and put in a jar soaked with alcohol, sealed in a cool and dry place, after a week can be used. Patients can rink $15 \mathrm{ml}$ daily in the morning (Figure 3).

Fourth is to use fallopia multiflora (200g), fructus lycii (50 g), syzygium aromaticum (15 g), honey (50 g), white wine 2,000 $\mathrm{ml}$. The herbs crushed and soaked with alcohol for 36 days are usable. Patients can take 2 times daily, $15-20 \mathrm{ml}$ each time (Figure 4).

\section{Some notes when using this treatment}

When using this treatment, patients should abstain from beets, onions and garlic. In addition, patients with low blood pressure or low blood sugar should also abstain. In addition, when using fallopia multiflora, it may interact with some medications that reduce the ability to treat and increase side effects. Therefore, the patient should pay close attention. ${ }^{13}$

There are some medicines may interact with fallopia multiflora. First is diuretics since its active ingredients contained in holopurian may increase the risk of hypokalemia if the patient is taken with diuretics. Second is anticoagulant. When used together, this herb can increase the side effects of antihypertensive drugs. Fallopia multiflora helps

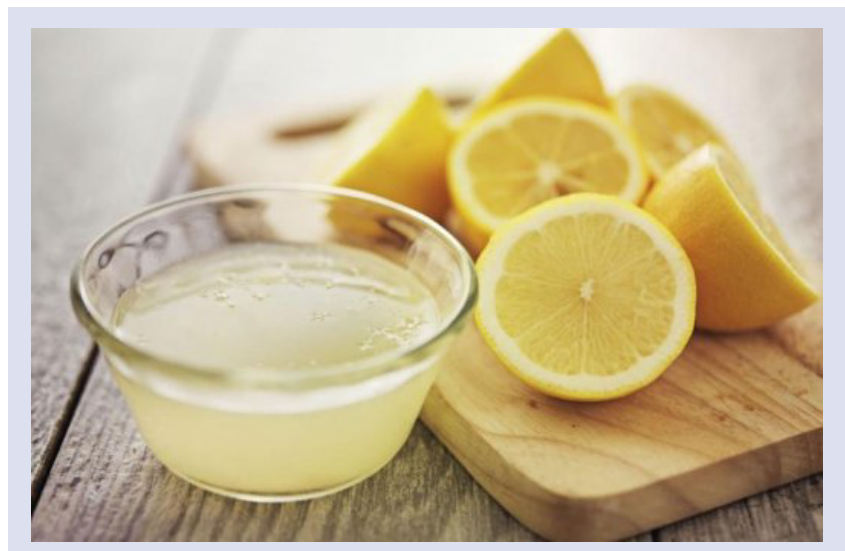

Figure 1: The combination of coconut oil and lemon.

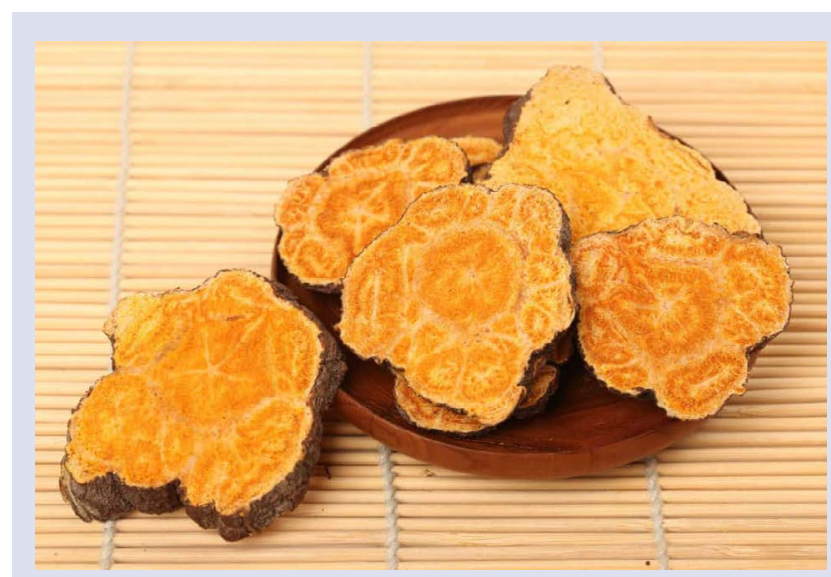

Figure 2: The image of fallopia multiflora.

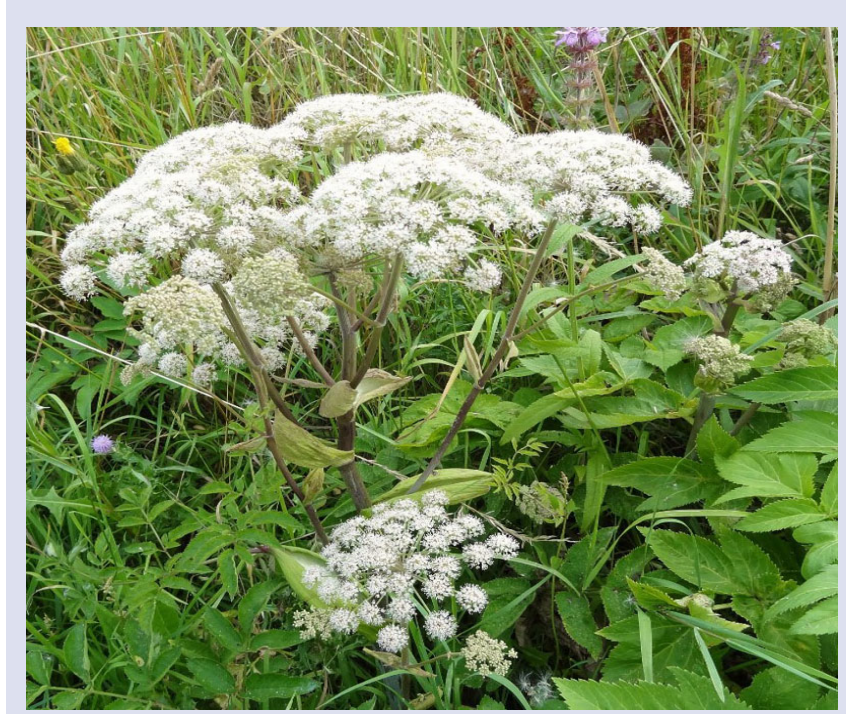

Figure 3: The image of angelica sinensis.

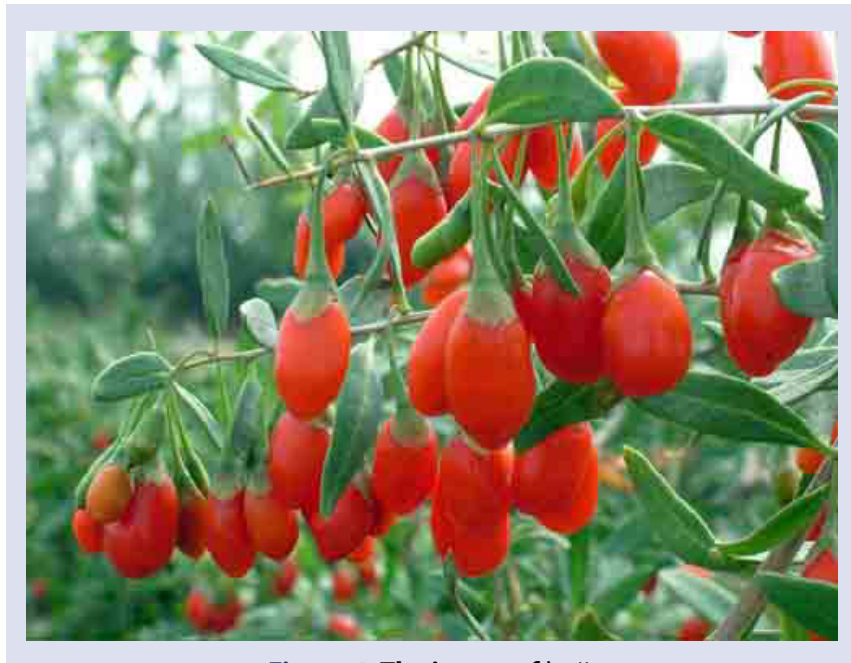

Figure 4: The image of lycii.

to smooth and darken hair, and has the effect of tonic, laxative, etc. However, the benefits to this health have not been specifically studied by science. Therefore, patients should not arbitrarily use without the consent of the physician.?

The three effects of fallopia multiflora. At least three special effects including blackening beard and hair; beneficial for childbirth and prolonging life.

Fallopia multiflora contains $1.7 \%$ anthraglycosides, including emodin, physcion, rhein, chrysophanol. In addition, in fallopia multiflora also contains $1.1 \%$ protid, $45.2 \%$ starch, $3.1 \%$ lipid, $4.5 \%$ inorganic substances, $26.45 \mathrm{~g}$ water-soluble substances, lecitin, rhaponticin (rhapontin), ponticin). Unprocessed fallopia multiflora contains $7.68 \%$ tannins; $0.25 \%$ of free anthraquinone derivatives; $0.8058 \%$ is a total anthraquinone derivative. After processing, there were $3.82 \%$ tannins; $0.1127 \%$ free anthraquinone derivative; $0.2496 \%$ total anthraquinone derivatives. The results of modern pharmacological studies have proven that polygonum has the effect of correcting dyslipidemia, helping to prevent atherosclerosis, protect liver cells, accelerate the production of red blood cells, improve immunity, improve the functioning of the endocrine gland system, especially the adrenal gland and thyroid gland. In addition, knotweed also has antibacterial effects, improve the body's ability to fight cold, laxative and detoxify. ${ }^{12}$ 
If we do not know how to use, fallopia multiflora is easily enlightened. Fresh fallopia multiflora contains compounds that stimulate intestinal motility, defecation causing diarrhea. Therefore, normal people if using fresh fallopia multiflora may have diarrhea. The processing of using fallopia multiflora must pay close attention to bring about the expected results.

\section{CONCLUSION}

It is not just gray hair that is due to our age. In fact, today, teenage-age teenagers with gray hair are not uncommon. Dye is only a temporary solution to treat gray hair early and will have serious consequences on the scalp later. Therefore, in order to prevent gray hair early, traditional medicine uses a lot of different methods to aim and nourish blood, in which the unique therapy is indispensable dish. However, knowing how to use the ingredients available in nature will help you significantly improve this situation. Fallopia multiflora has been proving its great effects that we can apply and coordinate with other types of pharmaceutical waste to get the best results and better hook, more confidence in life.

\section{ACKNOWLEDGEMENT}

The author would like to express warm thanks to FPT University, Vietnam for financial support.

\section{LIMITATIONS OF THE RESEARCH}

The article has not been studied in depth on the ingredients of herbal medicine to treat the disease much more effectively and this will be studied in the near future.

\section{ETHICAL CLEARANCE}

The author ensures the quality and integrity of the research. By writing this research paper, the author surely respects the confidentiality and anonymity of the research respondents since they participated in the work voluntarily.

\section{CONFLICTS OF INTEREST}

No conflicts of interest noted in the paper.

\section{REFERENCES}

1. Sleiman R, Kurban M, Succaria F, Abbas O. Poliosis circumscripta: overview and underlying causes. Journal of the American Academy of Dermatology 2013;69:625-33

2. Jalalat SZ, Kelsoe JR, Cohen PR. Alopecia areata with white hair regrowth case report and review of poliosis. Dermatology Online Journal. 2014;20.

3. Ediriwickrema LS, Liu CY, Kikkawa DO, Korn BS. Development of Poliosis Following Checkpoint InhibitorTreatment for Cutaneous Melanoma. Ophthalmic Plastic \& Reconstructive Surgery. 2019;35:e121-2.

4. Sheng SJ, Liu ZY, Zhao W, Shao L, Zhao SJ. Molecular analysis of a type II polyketide synthase gene in Fallopia multiflora. Biologia. 2010;65:939-46.

5. Ueda JY, TezukaY, Banskota AH, LeTran Q, Tran QK, Saiki I, et al. Antiproliferative activity of cardenolides isolated from Streptocaulon juventas. Biological and Pharmaceutical Bulletin. 2003;26:1431-5.

6. Bui HX, Nguyen DM, Le Tran Q. Chemical constituents of the root of streptocaulon juventas merr. Science and Technology Development Journal. 2011;14:28-35

7. Anaya-Eugenio GD, Addo EM, Ezzone N, Henkin JM, Ninh TN, et al. CaspaseDependent Apoptosis in Prostate Cancer Cells and Zebrafish by Corchorusoside C from Streptocaulon juventas. Journal of Natural Products. 2019;82:1645-55.

8. Nguyen OV, Eun JB. Antioxidant activity of solvent extracts from Vietnamese medicinal plants. Journal of Medicinal Plants Research. 2011;5:2798-811.

9. Ueda JY, Tezuka Y, Banskota AH, Tran QL, Tran OK, Saiki I, et al. Constituents of the Vietnamese medicinal plant Streptocaulon juventas and their antiproliferative activity against the human HT-1080 fibrosarcoma cell line. Journal of Natural Products. 2003;66:1427-33

10. Rani S. Management of Greying of Hairs (Sheeb) and Use of Hair Dyes (Khizaab) in Unani Medicine. Tang [Humanitas medicine]. 2018;8:7-7.

11. Stone PM. The Skin, Selected Dermatologic Conditions, and Medical Nutrition Therapy. In Integrative and Functional Medical Nutrition Therapy. 2020;9691002.

12. Sheng SJ, Liu ZY, Zhao W, Shao L, Zhao SJ. Molecular analysis of a type II polyketide synthase gene in Fallopia multiflora. Biologia. 2010;65:939-46.

13. Yan HJ, Fang ZJ, Fu J, Yu SX. The correlation between bioactive components of fallopia multiflora root and environmental factors. The American Journal of Chinese Medicine. 2010;38:473-83

\section{GRAPHICAL ABSTRACT}
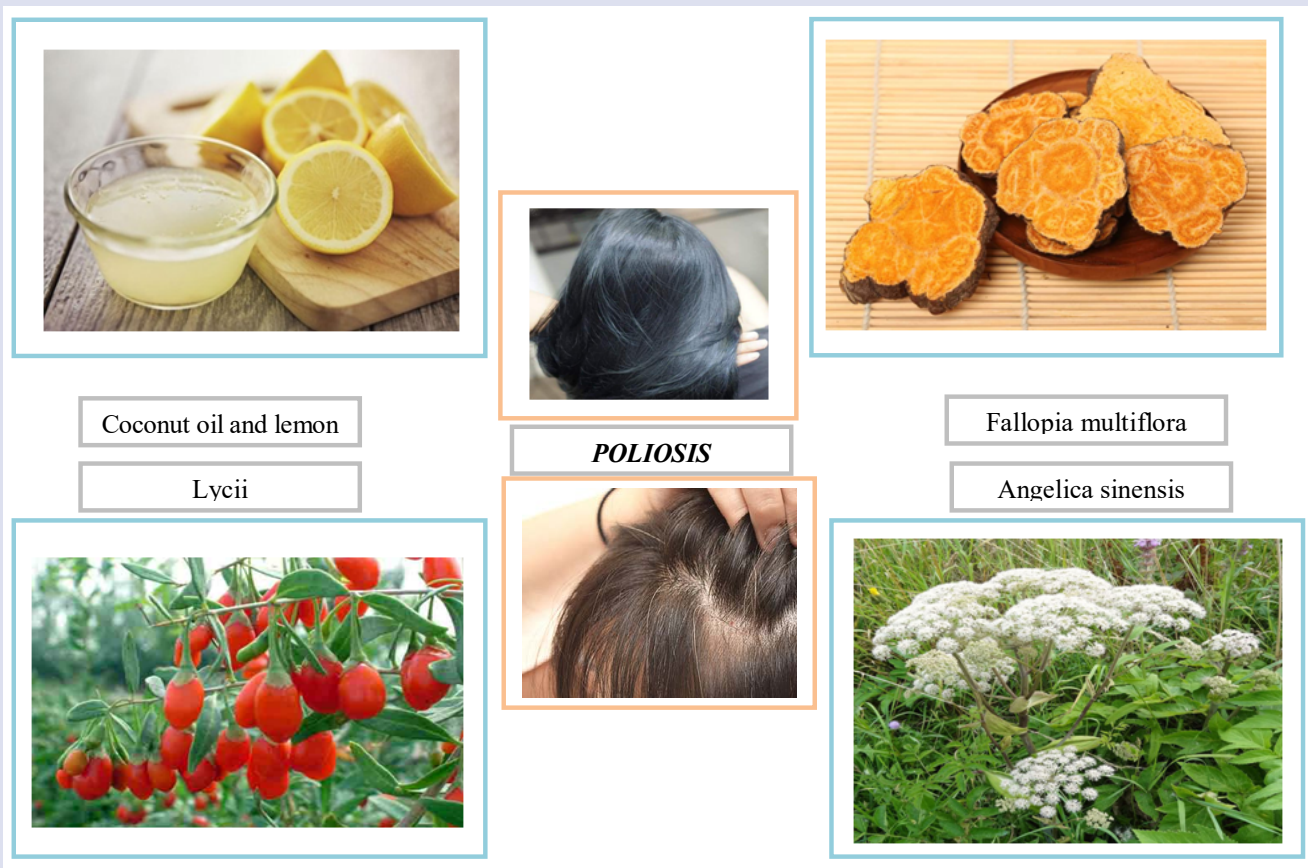


\section{ABOUT AUTHORS}

The author is now a Japanese lecturer of FPT University Ho Chi Minh City. His majors are literature, medication. He is now a Ph.D candidate. He can speak English, Japanese and Chinese.

Some recent publications:

1) Hoi, H. T. (2020). Some Kinds of Medicinal Herbs for the Treatment of Sinusitis. Biomedical and Pharmacology Journal, 13(2), 927-932.

2) Hoi, H. T. (2020). Herpes Virus, Causes of Infections and Preventive Methods. Jinu. M, Thankamma. P. George, NA Balaram, Sujisha. SS 2. Profile of Burn Deaths: A Study Based on Postmortem Examination of Burn Cases at RNT, 20(3), 330.

Cite this article: Hoi HT. Great Effect of Fallopia Multiflora and Other Herbs in Poliosis Treatment. Pharmacogn J. 2020;12(6) Suppl:1600-4. 